\title{
Aromatase immunoreactivity in fetal ovine neuronal cell cultures exposed to oxidative injury
}

\author{
G. Lepore, S. Gadau, A. Mura, M. Zedda, V. Farina \\ Department of Animal Biology, University of Sassari, Italy
}

(C2009 European Journal of Histochemistry

A lot of evidence testifies that aromatase is expressed in the central nervous system where it has been detected not only in hypothalamic and limbic regions but also in the cerebral cortex and spinal cord. In physiological conditions, aromatase is expressed exclusively by neurons, where it has been mainly found in cell bodies, processes and synaptic terminals. Moreover, primary cultured cortical astrocytes from female rats are more resistant to oxidant cell death than those from males, suggesting a protective role of estradiol. The aim of this study was to evaluate changes in aromatase expression in response to 3-nitro-L-tyrosine, a marker of oxidative stress, in primary neuronal cell cultures from brains of 60-day old sheep fetuses. Cells were identified as neurons by using class III $\beta$ tubulin, a marker of neuronal cells. Two morphological types were consistently recognizable: i) bipolar cells with an oval cell body; ii) multipolar cells whose processes formed a wide net with those of adjacent cells. In situ hybridization technique performed on 60-day old fetal neurons revealed that in baseline conditions aromatase gene expression occurs. Importantly, cells exposed to $360 \mu \mathrm{M}$ 3-nitro-L-tyrosine were fewer and showed more globular shape and shorter cytoplasmic processes in comparison to control cells. The immunocytochemical study with anti-aromatase antibody revealed that cells exposed to $360 \mu \mathrm{M}$ 3-nitro-L-tyrosine were significantly more immunoreactive than control cells. Thus, it can be postulated that the oxidant effects of the amino acid analogue 3nitro-L-tyrosine could be counterbalanced by an increase in aromatase expression that in turn can lead to the formation of neuroprotective estradiol via aromatization of testosterone.

Key words: 3-nitro-L-tyrosine, aromatase, oxidative injury, neuroprotection, neuronal cell cultures, sheep.

Correspondence: Gianluca Lepore

Department of Animal Biology, University of Sassari, Via Vienna, 207100 Sassari, Italy

Fax: +39.079.229432.

Tel.: +39.079.229593.

E-mail: lepore@uniss.it

Paper accepted on October 5, 2009

European Journal of Histochemistry

2009; vol. 53 issue 4 (October-December): 233-238
T he brain is an important site of steroid synthesis in vertebrates (Baulieu, 1997). Neuroendocrine tissue is capable of converting androgens into estrogens by the enzyme P450 aromatase (Naftolin et al., 1971). Estradiol, through its specific receptors, promotes many crucial regulatory effects on various processes, such as viability and survival of neurons in rat primary cultures (Chowen et al., 1992), neural differentiation and plasticity as well as sexual behavior. Aromatase modulates synaptic plasticity in the hippocampus and other brain regions related to cognition. The enzyme may also influence synaptic development and plasticity in other non-reproductive regions of the central nervous system. For instance, Purkinje cells in aromatase-knockout mice show decreased dendritic growth and impairment of formation of dendritic spines and synapses (Sasahara et al., 2007). In addition, numerous studies have shown expression, activity and distribution of aromatase in the central nervous system of rats (Shinoda et al., 1994) and humans (Yague et al., 2006). In the brain, aromatase is predominantly expressed in hypothalamic and limbic regions, but also other structures such as the cerebral cortex, midbrain and spinal cord reveal aromatase activity and immunoreactivity.

It has been demonstrated that aromatase is neuroprotective in the central nervous system. For instance, treatment with the neurotoxin kainic acid resulted in significant neuronal loss in the hippocampus of rats treated with the aromatase inhibitor fadrozole (Azcoitia et al., 2001). Under baseline conditions, aromatase is expressed in the central nervous system of mammals exclusively by neurons, where it has been mainly found in cell bodies, processes and synaptic terminals (Naftolin et al., 1996). Since aromatase is expressed in several cellular compartments, it can be supposed that it leads to the formation of estrogen that acts not only through the classical receptors but also 
by direct and rapid effects at neuronal membranes (Roselli, 2007).

Aromatase-expressing astrocytes have been observed in rats after stressful conditions such as serum deprivation or ischemia (Azcoitia et al., 2003, Roselli, 2007). The increased expression of aromatase in injured brain areas suggests that the enzyme may be involved in the protection of nervous tissue by increasing levels of local estrogens. Moreover, primary cultured cortical astrocytes from female rats are more resistant to oxidant cell death than males, suggesting estradiol has a protective role ( Liu et al., 2007). In particular, these Authors demonstrated that astrocytes isolated from neonatal cortex exhibit marked sex differences in the sensitivity to oxygen-glucose deprivation and oxidant cell death since female cells exhibited enhanced aromatization and estradiol formation.

The present investigation describes for the first time changes in aromatase expression in response to 3-nitro-L-tyrosine - a marker of oxidative stress - in primary neuronal cultures from fetal sheep brain.

\section{Materials and Methods}

Cells derived from the brains of twelve 60-day old sheep fetuses were obtained from local abbatoirs when pregnant sheep were slaughtered. The period of gestation was established measuring fetal crown-rump length, following the tables reported by McGeady et al. (2006). One fragment from each brain was suspended in ice-cold cell freezing medium composed of Dulbecco's modified Eagle's medium (DMEM) with $1 \%$ HEPES ( $\mathrm{pH} 7.4), 10 \%$ fetal calf serum and $10 \%$ dimethylsulfoxide (DMSO), following the cryopreservation method reported for neural tissue of bovine species (Hashimoto et al., 2000). Cryotubes were slowly cooled to $-80^{\circ} \mathrm{C}$ and transferred to liquid nitrogen the following day. Frozen tissues were rapidly thawed in a water bath at $38^{\circ} \mathrm{C}$ and minced in small fragments under sterile conditions. A papain dissociation system kit (Worthington Biochemical Corporation, Lakewood, NJ, USA) was used to dissociate cells. Cells were then suspended in a basal medium for cell culture consisting of a $1: 1$ mixture of DMEM and Ham's F12, supplemented with penicillin (30 $\mathrm{mg} / \mathrm{L})$, streptomycin (50 $\mathrm{mg} / \mathrm{L})$, sodium bicarbonate $(2.4 \mathrm{~g} / \mathrm{L})$, insulin $(10 \mu \mathrm{g} / \mathrm{mL})$, transferrin $(10 \mu \mathrm{g} / \mathrm{mL})$, sodium selenite $\left(10^{-8} \mathrm{M}\right)$ and $10 \%$ fetal calf serum, at $38^{\circ} \mathrm{C}$ in a $5 \% \quad \mathrm{CO}_{2}$ humidified atmosphere. Cells were plated on glass coverslips, previously coated with poly-L-lysine (Sigma, St. Louis, M0, USA). Twenty coverslips from each fetal brain were obtained.

One monolayer per brain was used to characterize neurons by the immunofluorescence method. Briefly, at day 10 of culture, cells were fixed with $4 \%$ paraformaldehyde at room temperature for 30 min. After fixation, cells were washed with PBS, then permeabilized with $0.1 \%$ Triton X-100 for $15 \mathrm{~min}$ at room temperature and incubated overnight with a monoclonal antibody anti-class III $\beta$-tubulin (Sigma), a widely-recognized marker of neuronal cells, diluted 1:200. Cells were then incubated for $1 \mathrm{~h}$ at $37^{\circ} \mathrm{C}$ with the antimouse FITC-conjugated antibody (Sigma) diluted 1:100. In addition, nuclei were counterstained with Hoechst \#33258 fluorescent dye. One additional monolayer per brain was used as negative control by omitting the primary antibody or employing non-immune mouse serum. Cells were finally examined by confocal microscopy.

In order to detect aromatase gene expression in baseline conditions, in situ hybridization technique was performed. A melting curve ranging $37^{\circ}$ to $42^{\circ} \mathrm{C}$ was performed in a preliminary study carried out at our labs, indicating $38^{\circ} \mathrm{C}$ as the optimal temperature. On one monolayer per brain biotinylated cDNA probe with a 48-nucleotide sequence from Sigma was pipetted and followed by incubation with streptavidin peroxidase complex and diaminobenzidine as chromogen. A second monolayer was incubated with sense probe and displayed no signal.

In addition, 5 monolayers per brain underwent $72 \mathrm{hr}$-exposure to 180 (2 coverslips) and $360 \mu \mathrm{M}$ (3 coverslips) 3-nitro-L-tyrosine. Aromatase immunoreactivity was then detected by immunoperoxidase technique. The concentration of 180 and $360 \mu \mathrm{M}$ 3-nitro-L-tyrosine were chosen as they were able to determine morphological alterations in C1300 murine neuroblastoma cell line (Zedda et al., 2004).

In detail, cells were blocked for 20 min with normal goat serum and incubated overnight at $4^{\circ} \mathrm{C}$ with a polyclonal anti-aromatase antibody obtained from rabbit $(5 \mu \mathrm{g} / \mathrm{mL}$, Acris, 
Hiddenhausen, Germany) diluted 1:200, then for Ih in biotinylated goat anti-rabbit antibody (Vector, Burlingame, CA, USA) diluted 1:250. This antibody recognises aromatase from numerous Mammalian species including bovine and sheep, as specified by Acris. After several rinses in $P B S$, sections were incubated with avidin-biotin complex system ( $A B C$, Vector) for $30 \mathrm{~min}$. Coverslips were then incubated with diaminobenzidine (DAB) for 1-5 min and finally dehydrated and mounted on slides. A second polyclonal antibody from Sigma confirmed the results. Both antibodies were preliminarily tested with Western blot using fetal sheep brain.

Five additional monolayers per brain underwent the protocol above without 3-nitro-L-tyrosine and served as controls. Quantitative analysis of immunocytochemical results was performed by means of Image $\mathrm{J} 1.42 \mathrm{q}$ software $(\mathrm{NIH}$, Bethesda MD, USA) which detects variations of staining between $360 \mu \mathrm{M}$ 3-nitro-L-tyrosinetreated and untreated cells. Averages $\pm S D$ from the data obtained are reported in the diagram in Figure 6.

A further six monolayers per sample, namely three cultured under baseline conditions and three after $72 \mathrm{hr}-360 \mu \mathrm{M}$ 3-nitro-L-tyrosine exposure, were used to carry out viability assay with a mixture of Hoechst \#33258 and propidium iodide dyes and observed by confocal microscope.

\section{Results}

In the living state and baseline conditions cells were numerous and viable and they grew to and adhered well on glass coverslips. Their cell bodies were spindle-like, oval- or triangular-shaped with long processes that tended to have contacts with those of the contiguous cells (Figure 1). The immunofluorescence method revealed that more than $90 \%$ of cultured cells could be identified as neurons, since they were class III $\beta$-tubulin positive. Two types of cells were detected: i) bipolar cells with an oval cell body and two long processes that originated from the opposite poles; ii) multipolar cells whose processes formed a wide net with those of adjacent cells (Figure 2). In situ hybridization technique showed that at gestation day 60, aromatase was expressed in fetal sheep brain, as shown in Figure 3. Treatment with 180

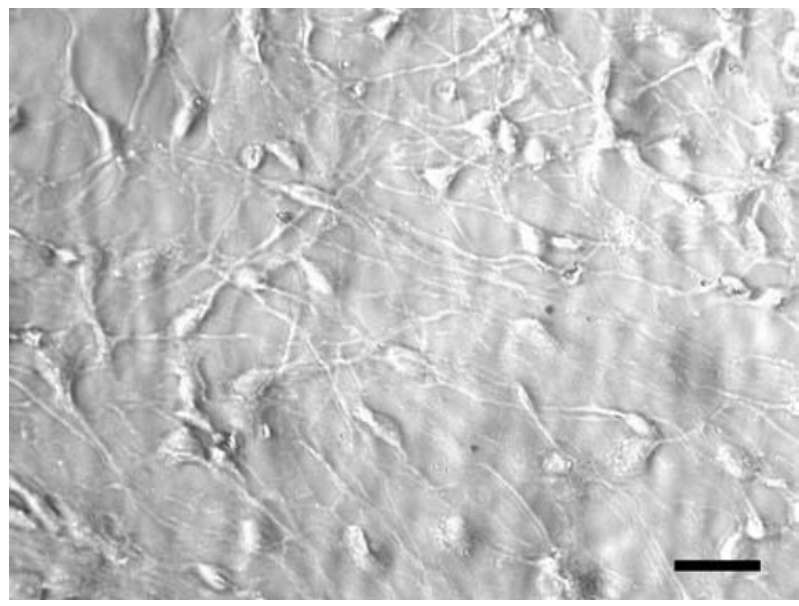

Figure 1. Phase contrast optics. Cells from 60-day old sheep fetuses. Cells are numerous and viable, oval- or triangularshaped with long processes that tend to have contacts with those of the contiguous cells. Scale bar: $80 \mu \mathrm{m}$.

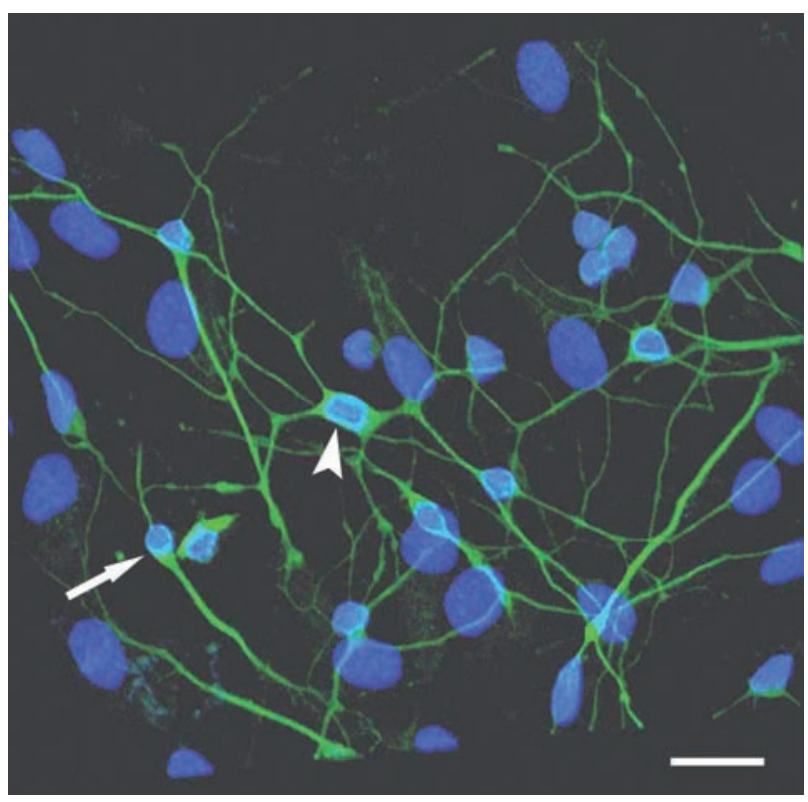

Figure 2. Confocal laser scanning microscopy. Most cells are positive to neuron-specific class III $\beta$-tubulin and show bipolar (arrow) and multipolar (arrowhead) shape as well as long cytoplasmic processes forming a wide net. Scale bar: $40 \mu \mathrm{m}$.

$\mu M$ 3-nitro-L-tyrosine (Figure 4B) did not determine any significant change in cell number and morphology in comparison with controls (Figure $4 \mathrm{~A}$ ). In contrast, cells exposed to $360 \mu \mathrm{M}$ 3nitro-L-tyrosine (Figure $4 \mathrm{C}$ ) were reduced in number and showed a more globular shape and shorter cytoplasmic processes in comparison to control cells. In addition, $360 \mu \mathrm{M}$ 3-nitro-L-tyrosine-exposed cells displayed intracytoplasmic vac- 
uols as a consequence of cell suffering (Figure 4D).

The immunocytochemical method with antiaromatase antibody revealed that cells exposed to $360 \mu \mathrm{M}$ 3-nitro-L-tyrosine were significantly more immunoreactive than control cells (Figure 5). Although aromatase immunoreactivity was mainly detected in cell bodies, few cells displayed immunostained cytoplasmic processes as well. The quantitative analysis of anti-aromatase immunocytochemical results reported in the diagram of Figure 6 indicates statistically significant differences between percentages of stained cells in $360 \mu \mathrm{M}$ 3-nitro-L-tyrosine-treated and untreated cultures.

Finally, cell viability assay did not show any significant difference between controls and $72 \mathrm{hr}$ $360 \mu \mathrm{M}$ 3-nitro-L-tyrosine-exposed monolayers.

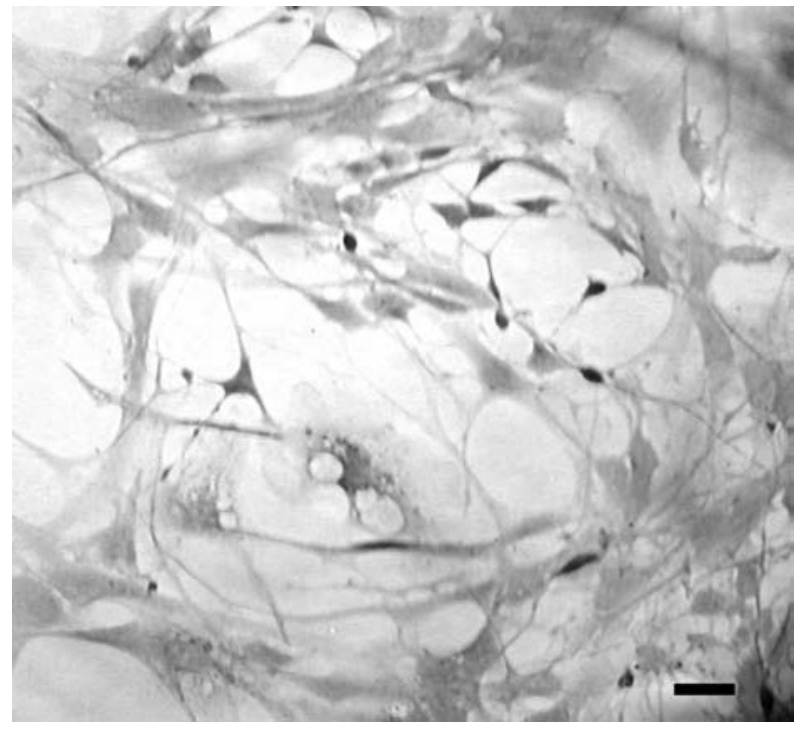

Figure 3. In situ hybridization study shows that aromatase is expressed in cultured cells at gestation day 60 and in baseline conditions. Scale bar: $\mathbf{4 0} \mu \mathrm{m}$.
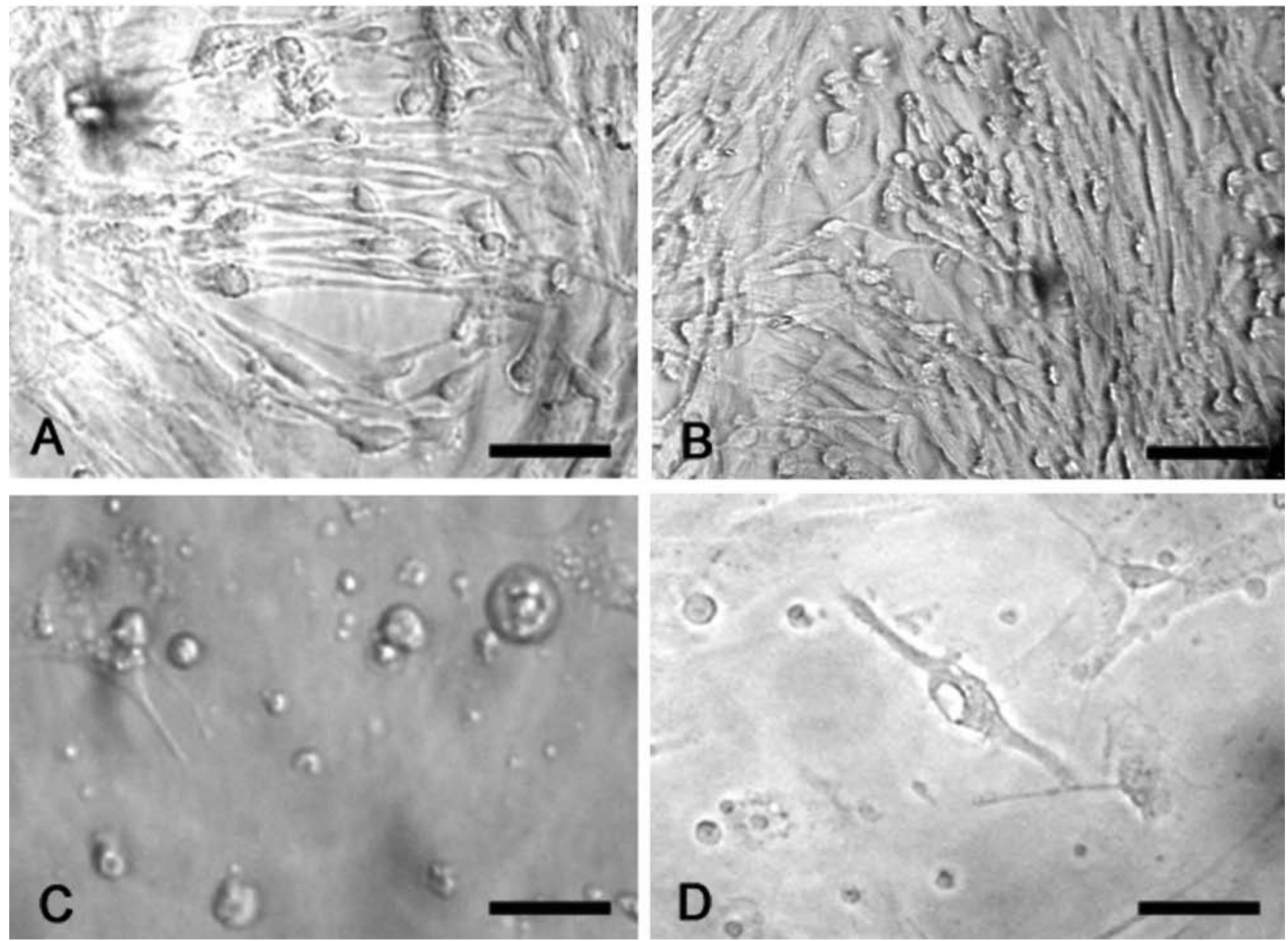

Figure 4. Phase contrast optics. Cells exposed to $180 \mu \mathrm{M}$ 3-nitro-L-tyrosine (B) do not show any significant change in cell number and morphology in comparison with controls (A). Cells exposed to $360 \mu \mathrm{M}$ 3-nitro-L-tyrosine (C) show globular shape, short cytoplasmic

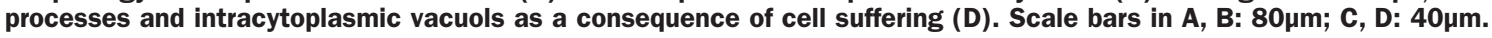




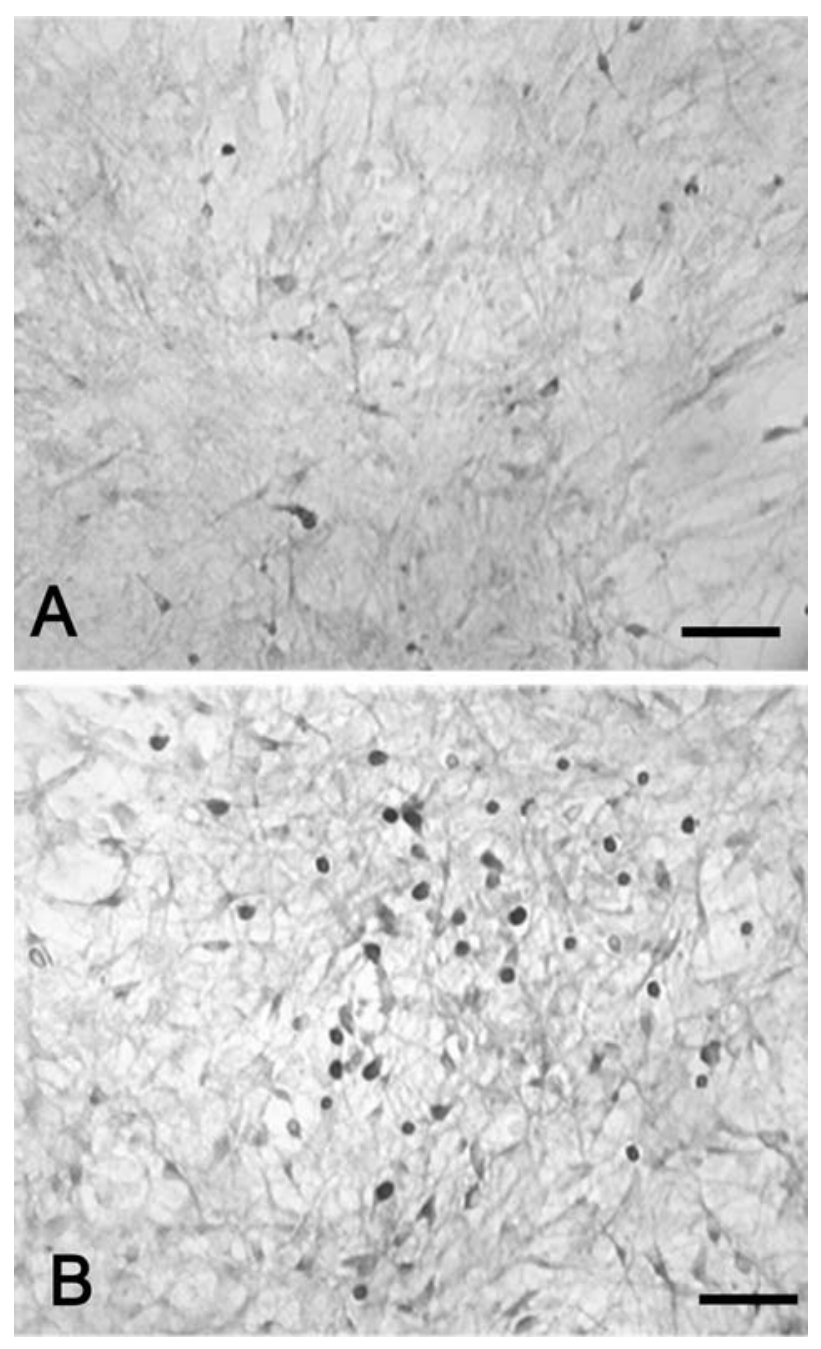

Figure 5. Immunocytochemical study. Cells exposed to $360 \mu \mathrm{M}$ 3-nitro-L-tyrosine (B) exhibit a higher aromatase immunoreactivity than control cells (A). Note that aromatase immunoreactivity is mainly confined to the cell body. Scale bar: $100 \mu \mathrm{m}$.

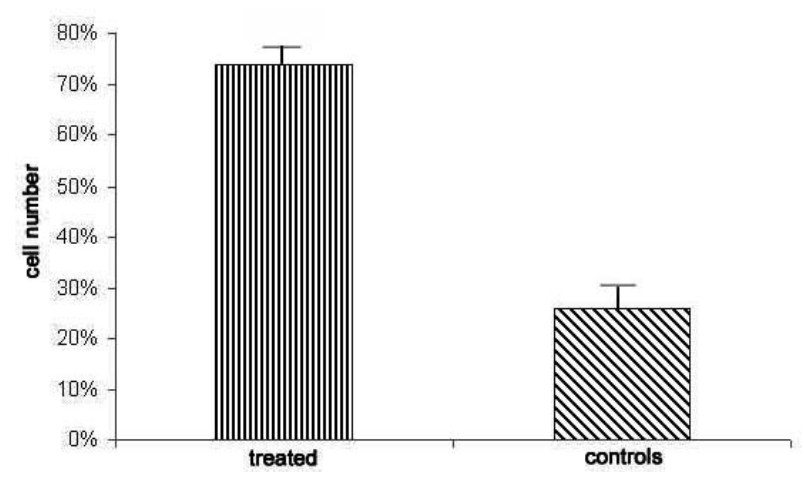

Figure 6. Significant difference in the number of aromataseimmunopositive cells in $\mathbf{3 6 0} \mu \mathrm{M}$ 3-nitro-L-tyrosine-exposed cultures and controls expressed in percentage, $p<0.5$.

\section{Discussion}

The present work shows for the first time changes in aromatase expression in response to 3nitro-L-tyrosine, a marker of oxidative stress, in primary neuronal cultures from fetal sheep brain. In this study a relatively simple method to obtain pure cell cultures from fetal sheep brain is presented. This method is based on what reported by Peruffo et al. (2004) who describe a protocol of obtaining primary cultures from the cerebral cortex and hypothalamus of bovine fetuses. According to these Authors, successful outcomes may depend on the brain region of cell collection, developmental stage and culture medium conditions. Such parameters are indeed capable of influencing cell differentiation, as well as the ratio between neurons and glial cells. Explants from cortex at early stages (10th week of pregnancy) yielded maximum amounts of neurons. In agreement with their reports, numerous and viable cells that grew to and adhered well on glass coverslips could be obtained in our study from the brain cortex and at early stage of sheep pregnancy (60th day). In such conditions, about $90 \%$ of growing cells were neurons (Peruffo et al., 2004).

In our work, more than $90 \%$ of cultured cells were class III $\beta$-tubulin positive with bipolar and multipolar shape and long cytoplasmic processes forming a wide net. In this case, sheep cells behave like amphibian neurons where class III $\beta$-tubulin immunoreactivity is accompanied by the differentiation of cytoplasmic processes (Moody et al., 1996). Our data are consistent with the report of Kay et al. (2006), who set up cortical and cerebellar neurons from 9 to 15 -week old fetal sheep brains. Nearly all the cells cultured by these Authors from the youngest fetuses (9 weeks old) adhered as neurons. According to these Authors, the proportion of glial cells increased with age, as well as the risk of cultures of being overtaken by glial cells.

In our study, cells from fetuses at gestation day 60 and under baseline conditions express aromatase as revealed by in situ hybridization technique. This datum is in agreement with previous studies demonstrating the presence of aromatase activity in neurons obtained from hypothalamus of 14-15 day-old rat embryos (Negri Cesi et al., 1992), as well as in diverse brain regions such as the hippocampus (Yague et al., 2008). Cells 
exposed to $360 \mu \mathrm{M}$ 3-nitro-L-tyrosine exhibited morphological changes as they became globularshaped and reduced their cytoplasmic processes. This could be due to the action of 3-nitro-L-tyrosine on microtubules. Indeed, a previous work of ours showed that cell lines of neuronal and glial origin exposed to $360 \mu \mathrm{M}$ 3-nitro-L -tyrosine underwent morphological changes and nuclear suffering as a result of nitrotyrosination of $\alpha$ tubulin and consequent impairment of microtubular network (Zedda et al., 2004).

It is of interest that the treatment of cells with 3-nitro-L-tyrosine resulted in a higher aromatase immunoreactivity than control cells. The oxidant action of the amino acid analogue 3-nitro-L-tyrosine could be counterbalanced by an increase in aromatase expression that in turn can lead to the formation of neuroprotective estradiol via aromatization of testosterone. Indeed, the neuroprotective properties of estradiol have been well documented (Behl, 2002) and a greater resistance against oxidant injury has been detected in female rat astrocytes than in males (Liu et al., 2007).

In conclusion, our in vitro model could be useful to study the variations in aromatase expression in cells of neural origin and may contribute to a better understanding of some mechanisms of neurodegenerative disorders in which estrogens play a crucial role as antioxidant agents.

\section{References}

Azcoitia I, Sierra A, Veiga S, Garcia-Segura LM. Aromatase expression by reactive astroglia is neuroprotective. Ann N Y Acad Sci 2003; 1007:298-305.

Azcoitia I, Sierra A, Veiga S, Honda S, Harada N, Garcia-Segura LM Brain aromatase is neuroprotective. J Neurobiol 2001;47:318-29.

Baulieu E.E. Neurosteroids: of the nervous system, by the nervous system, for the nervous system. Recent Prog Hor Res 1997;52:1-32.
Behl C. Oestrogen as a neuroprotective hormone. Nat Rev Neurosci $2002 ; 3: 433-42$

Chowen JA, Torres-Alemán I, García-Segura LM. Trophic effects of estradiol on fetal rat hypothalamic neurons. Neuroendocrinology 1992;56:895-901.

Hashimoto $A$, Onodera $T$, Ikeda $H$, Kitani $H$. Isolation and characterisation of fetal bovine brain cells in primary culture. Res Vet Sci 2000;69:39-46.

Kay GW, Oswald JM, Palmer DN. The development and characterisation of complex ovine neuron cultures from fresh and frozen fetal neurons. J Neurosci Methods 2006;155:98-108.

Liu M, Hurn PD, Roselli CE, Alkayed NJ. Role of P450 aromatase in sex-specific astrocytic cell death. J Cereb Blood Flow Metab 2007;27:135-41.

McGeady TA, Quinn PJ, FitzPatrick ES, Ryan MT. Veterinary Embryology, Blackwell Publishing, Oxford, 2006.

Moody SA, Miller V, Spanos A, Frankfurter A. Developmental expression of a neuron-specific beta-tubulin in frog (Xenopus laevis): a marker for growing axons during the embryonic period. J Comp Neurol 1996;364:219-30.

Naftolin F, Horvath TL, Jakab RL, Leranth C, Harada N, Balthazart J. Aromatase immunoreactivity in axon terminals of the vertebrate brain. An immunocytochemical study on quail, rat, monkey and human tissues. Neuroendocrinology 1996;63:149-55.

Naftolin F, Ryan KJ, Pedro Z. Aromatization of androstenedione by the diencephalon. J Clin Endocrinol Metab 1971;33:368-70.

Negri Cesi P, Melcangi RC, Celotti F, Martini L. Aromatase activity in cultured brain cells: difference between neurons and glia. Brain Res 1992;589:327-32.

Peruffo A, Massimino ML, Ballarin C, Carmignoto G, Rota A, Cozzi B. Primary cultures from fetal bovine brain. Neuroreport 2004; 15:1719-22.

Roselli CF. Brain aromatase: roles in reproduction and neuroprotection. J Steroid Biochem Mol Biol 2007;106:143-50.

Roselli CE, Stormshak F, Resko JA. Distribution of aromatase mRNA in the ram hypothalamus: an in situ hybridization study. J Neuroendocrinol 2000;12:656-64.

Sasahara K, Shikimi H, Haraguchi S, Sakamoto H, Honda S, Harad N, Tsutsui K. Mode of action and functional significance of estrogeninducing dendritic growth, spinogenesis and synaptogenesis in the developing Purkinje cell. Neurosci 2007;27:7408-17.

Shinoda K, Nagano M, Osawa Y. Neuronal aromatase expression in preoptic, strial, and amygdaloid regions during late prenatal and early postnatal development in the rat. J Comp Neurol 1994;343: 113-29.

Yague JG, Muñoz A, de Monasterio-Schrader P, Defelipe J, GarciaSegura LM, Azcoitia I. Aromatase expression in the human temporal cortex. Neuroscience 2006;138:389-401.

Yague JG, Wang AC, Janssen WG, Hof PR, Garcia-Segura LM, Azcoitia I, Morrison JH. Aromatase distribution in the monkey temporal neocortex and hippocampus. Brain Res 2008;1209:115-27.

Zedda M, Lepore G, Gadau S, Manca P, Farina V. Morphological and functional changes induced by the amino acid analogue 3-nitrotyrosine in mouse neuroblastoma and rat glioma cell lines. Neurosci Lett 2004; 10:190-3. 